\title{
Early PET-CT After Stereotactic Radiotherapy for Stage 1 Non-small Cell Lung Carcinoma Is Predictive of Local Control
}

\author{
MARGUERITE TYRAN $^{1}$, NATHALIE CHARRIER ${ }^{2}$, JULIEN DARREON $^{1}$, \\ ANNE MADROSZYK $^{3}$, AGNES TALLET $^{1}$ and NAJI SALEM ${ }^{1}$ \\ Departments of ${ }^{1}$ Radiation Oncology, ${ }^{2}$ Nuclear Medicine, and \\ ${ }^{3}$ Medical Oncology, Paoli-Calmettes Institute, Marseille, France
}

\begin{abstract}
Background/Aim: Radiological evaluation after stereotactic-body-radiotherapy (SBRT) for non-small-cell lung carcinoma (NSCLC) is often difficult due to lung radiation-induced image modifications on computed tomographic (CT) scan. The aim of this study was to evaluate positron-emission tomography-computed tomography (PET-CT) using fluorodeoxyglucose after SBRT in primary lung cancer. Patients and Methods: Eighteen patients with histologically proven NSCLC were treated with SBRT. All had PET-CT evaluations before treatment, at 2 to 3 months and at 1 year post SBRT during the follow-up. Results: Early PET-CT in 12/18 patients who did not experience local failure did not show any progression. No conclusion could be drawn in four cases because early PET$C T$ was disturbed by inflammatory reaction. Early PET-CT was not predictive of late outcome for two patients, as it showed a significant response followed by disease progression on late evaluation. Conclusion: Early PET response appears to correlate with local control at 1 year post SBRT.
\end{abstract}

Stereotactic body radiotherapy (SBRT) in early-stage nonsmall-cell lung carcinoma (NSCLC) has increased over the past years. SBRT is an effective treatment (1) and could be an alternative to surgery for early-stage T1-T2 disease (2). Recommendations for the follow-up of early stages following SBRT include monitoring every 6 months for 2-3 years and

This article is freely accessible online.

Correspondence to: Naji Salem, Department of Radiation Oncology, Institut Paoli-Calmettes, 232 Boulevard Sainte Marguerite, 13009 Marseille, France. Tel: +33 0491223637, Fax: +330491223559, e-mail: salemn@ipc.unicancer.fr

Key Words: Lung cancer, SBRT, PET-computed tomographic, local control. chest computed tomography (CT) (3). Radiological evaluation is based on Response Evaluation Criteria in Solid Tumors (RECIST) criteria (4). However, numerous studies have criticized the use of RECIST criteria for radiological evaluation after SBRT because of radiation-induced modifications in the treatment fields $(5,6)$ due to inflammation and fibrosis. The use of biopsies to assess local relapse could be reduced by better radiological discrimination.

For this purpose, studies have tried to assess the predictive impact of positron-emission tomography-computed tomography (PET-CT) for response evaluation of NSCLC after high-dose radiotherapy. Indeed, it has been observed that metabolic changes in tumor were more significant than anatomical changes 12 weeks after SBRT (7). PET after SBRT has been explored with different timings in monocentric series (8-13). The use of PET is hampered by frequent metabolic modifications on images after SBRT (in $62 \%$ at 6 months) (14), therefore some teams $(15,16)$ claim that PET should be interpreted with caution for 2 years after SBRT and may only be used in case of relapse suspicion according to European Society of Medical Oncology guidelines (3) and the algorithm proposed by Huang et al. (14).

Nevertheless, it has been observed that these modifications appear between 3 and 6 months after SBRT for acute reactions and may persist with low metabolic activity up to 2 years for late effects. This study examined metabolic response using early PET, performed earlier than 6 months after SBRT, as an early surrogate of treatment response.

\section{Patients and Methods}

Patients and treatment. The study was approved by the local Ethic Committee (number 2017-005) and 18 patients were included between February 2013 and October 2014. Pre-treatment evaluation included medical history, clinical examination, tumor histology and ${ }^{18}$ F-fluorodeoxy-glucose (FDG) PET-CT. Patients did not undergo any prior radiation therapy. They were treated with SBRT, using 3D conformational radiotherapy technique. They all had a histologically proven diagnosis. Ten patients were diagnosed with adenocarcinoma 
and eight with squamous-cell carcinoma. The median age of patients at treatment time was 75.5 years (range $=55-85$ years) (Table I).

Patients were immobilized before each treatment session with a vacuum pillow and abdominal compression. A scanner-guided simulation was performed with the construction of a maximumintensity projection. The internal target volume was delineated on the maximum-intensity projection reconstruction. The planning target volume (PTV) was constructed by adding $0.3 \mathrm{~cm}$ in the axial plane and $0.5 \mathrm{~cm}$ in the longitudinal plane. They all had an identical delivered dose of 48Gy in six fractions of 8 Gy and a median duration of treatment of 9 days. Dose was prescribed to the $82-90 \%$ isodose to allow PTV coverage. Lung lesions had a median size of $19.5 \mathrm{~mm}$ and median CTV and PTV were $12 \mathrm{~cm}^{3}$ and 37.4 $\mathrm{cm}^{3}$, respectively. All patients underwent PET-CT 1 to 2 months before the treatment and had the same examination sequentially after the therapy, which was reviewed by the same nuclear physician for the study.

FDG-PET-CT follow-up and analysis. Fasting blood glucose level was detained before PET-CT to ensure reliable results. After $3.5 \mathrm{MBq} / \mathrm{kg}$ of FDG was injected, 45 to $90 \mathrm{~min}$ was allowed for uptake. A non-contrast CT scan was acquired from the base of the skull through the inguinal region, followed by a 3D emission scan of the same area.

A minimum of two PET-CTs were required during the follow-up: one early 2 to 3 months after SBRT and the second 12 months after treatment. The maximum standardized uptake value $\left(\mathrm{SUV}_{\max }\right)$ of the tumor bed and lung background noise $\left(\mathrm{SUV}_{\mathrm{bgn}}\right)$ were listed. A ratio between those two values of 1 (range $=0.75-1.25$ ) was defined as inflammatory reaction, leading to uninterpretable results. No

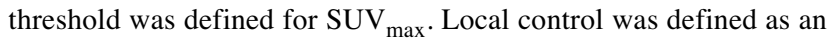
$\mathrm{SUV}_{\max }$ reduction or stabilization, and local failure as an increase in $\mathrm{SUV}_{\max }$ by over $50 \%$ from the baseline, with an increase in the size of the lesion.

\section{Results}

Median follow-up was 28 months (range=16-38 months). Two patients experienced local relapse in the treated volume after SBRT. Before treatment, the median $\mathrm{SUV}_{\max }$ was 8.9 (range=2.2-29). On first evaluation according to early PEC$\mathrm{CT}$, a metabolic response, judged as $\mathrm{SUV}_{\max }$ decrease, was noted for 13 patients (72.2\%). Two out of these 13 patients developed local failure at the second PET-CT examination. One patient had a metabolic progression on early PET-CT but achieved a metabolic response at the second evaluation at 12 months. Four patients were considered as being nonevaluable on first PET-CT scan due to inflammatory reactions. These four patients had a low pretreatment FDG tumor uptake with low $\mathrm{SUV}_{\max }$ (median $\mathrm{SUV}_{\max }=3.1$ ) as compared to the patients whose $\mathrm{SUV}_{\max }$ decreased (median $\mathrm{SUV}_{\max }=12$ ) Results are presented in Table II.

On late evaluation 1 year following SBRT, $61 \%$ of the patients $(11 / 18)$ had a decrease in their $\mathrm{SUV}_{\max }$, while $27.7 \%(5 / 18)$ had no modification of $\mathrm{SUV}_{\max }$ compared to early PET-CT. Two patients with an initial decrease of $\mathrm{SUV}_{\max }$ on early PET-CT experienced local recurrence.
Table I. Baseline patient characteristics.

\begin{tabular}{lc}
\hline Characteristic & $\mathrm{N}=18$ \\
\hline Male/female, $\mathrm{n}$ & $14 / 4$ \\
Median age (range), years & $75.5(55-85)$ \\
Median SUV $_{\max }$ (range) & $8.9(2.2-29)$ \\
Tumor stage*, & \\
T1a, N0 & 10 \\
T1b, N0 & 7 \\
T2a, N0 & 1 \\
Median tumor diameter (range), mm & $19.5(6-40)$ \\
Pathology, $\mathrm{n}$ & 10 \\
Adenocarcinoma & 8 \\
Squamous-cell carcinoma & \\
\hline
\end{tabular}

*TNM 7th edition.

\section{Discussion}

In this series, we observed that evaluation with PET after SBRT, for NSCLC led to reliable interpretation when carried out between 2 and 3 months after treatment. According to our results, early PET-CT evaluation following lung SBRT was predictive of late evaluation for $11 / 18$ patients who did not experience local failure as their early PET-CT did not indicate progression. In four cases no conclusion could be drawn because early and late PET-CT was disturbed by inflammatory reactions. Early PET-CT was not predictive of late outcome for three patients: one experienced an increased $\mathrm{SUV}_{\text {max }}$ on the first imaging which decreased on the late PET examination; in contrast, two had an early decrease of $\mathrm{SUV}_{\text {max }}$ and an increase of $\mathrm{SUV}_{\max }$ on the following PETCT 1 year after SBRT completion.

This study has several limitations due to its retrospective design and the small number of patients included. Since most patients with stage 1 lung carcinoma are often referred to surgery, only patients unfit for lung surgery are treated with SBRT. We did not include patients treated for oligometastatic disease to the lung, which comprise the major proportion of SBRT treatments, because of patient heterogeneity and systemic treatments that could interfere with PET-CT response. Nevertheless, our population was homogeneous for the technique of SBRT, prescribed dose to the tumor volume and PET-CT acquisition and interpretation. The SBRT technique (17) and dose level (18) were reported to influence metabolic images, leading to difficulty to applying observations made by others.

We used the $\mathrm{SUV}_{\text {max }}$, which is the most commonly used in other series and the most reproducible (19), as an evaluation criterion. Interpretation and comparison of SUV values is difficult, depending on technical, biological and physical parameters (20). Although an $\mathrm{SUV}_{\max }$ of 5 is frequently proposed as a threshold $(14,21)$, no extrapolation 
Table II. Details per patient of pretreatment, early and late positron-emission tomography-computed tomography (PET-CT) evaluation results.

\begin{tabular}{|c|c|c|c|c|c|c|c|}
\hline \multirow{3}{*}{ Patient no. } & \multicolumn{6}{|c|}{ PET-CT time point } & \multirow[b]{3}{*}{ Result } \\
\hline & \multicolumn{2}{|c|}{ Pretreatment } & \multicolumn{2}{|c|}{ Early (2-3 months) } & \multicolumn{2}{|c|}{ Late (11-14 months) } & \\
\hline & $\mathrm{SUV}_{\max }$ & $\mathrm{SUV}_{\text {bgn }}$ & $\mathrm{SUV}_{\text {max }}$ & $\mathrm{SUV}_{\mathrm{bgn}}$ & $\mathrm{SUV}_{\max }$ & $\mathrm{SUV}_{\mathrm{bgn}}$ & \\
\hline 1 & 11.2 & 2.4 & 4 & 0.6 & 3.7 & 0.5 & $\mathrm{LC}$ \\
\hline 2 & 2.2 & 0.9 & 4.8 & 1.6 & 1.1 & 3.2 & $\mathrm{LC}$ \\
\hline 3 & 6.7 & 0.5 & 1.8 & 0.5 & 18.6 & 0.5 & LF \\
\hline 4 & 3 & 1.3 & 2.7 & 1.5 & 3 & 3 & IR \\
\hline 5 & 2.4 & 0.5 & 4 & 2.3 & 3 & 3.3 & IR \\
\hline 6 & 7 & 0.5 & 2.2 & 0.5 & 2 & 0.5 & LC \\
\hline 7 & 6.3 & 0.2 & 3.2 & 0.7 & 2.3 & 1 & LC \\
\hline 8 & 29 & 0.9 & 12.3 & 1.8 & 2.7 & 1 & $\mathrm{LC}$ \\
\hline 9 & 21.3 & 1.2 & 5.1 & 0.6 & 1.7 & 2.3 & $\mathrm{LC}$ \\
\hline 10 & 3.2 & 0.9 & 5 & 5.1 & 3.6 & 3.6 & IR \\
\hline 11 & 17.5 & 0.9 & 3.4 & 1.2 & 1.6 & 2 & LC \\
\hline 12 & 7.3 & 0.8 & 5.6 & 1.9 & 5.2 & 2.4 & IR \\
\hline 13 & 23 & 0.9 & 10.5 & 1.4 & 2 & 0.9 & LC \\
\hline 14 & 12 & 0.8 & 5.1 & 1.3 & 2.0 & 1.6 & LC \\
\hline 15 & 17 & 1.1 & 3.5 & 0.9 & 3.4 & 1.3 & LC \\
\hline 16 & 9.8 & 0.7 & 2.8 & 1.5 & 1.6 & 2.6 & LC \\
\hline 17 & 20.6 & 0.9 & 4.5 & 1.6 & 2.4 & 1.6 & LC \\
\hline 18 & 8 & 0.5 & 3.2 & 1.2 & 10.5 & 0.9 & LF \\
\hline
\end{tabular}

$\mathrm{SUV}_{\max }$ : Maximum standardized uptake value; $\mathrm{SUV}_{\mathrm{bgn}}$ : standardized uptake value background noise; LC: local control; LF: local failure; IR: inflammatory reaction.

can be made from data of other centers because of different technical parameters $(22,23)$.

The four patients with uninterpretable results in our patient set had a low initial $\operatorname{SUV}_{\max }(<5)$. This was also reported in a study of patients treated with hypofractionated SBRT (11); these authors concluded that patients with low

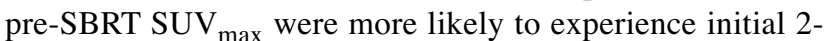
week rises in $\mathrm{SUV}_{\text {max }}$, while patients with high pre-SBRT $\mathrm{SUV}_{\text {max }}$ commonly had a decline in $\mathrm{SUV}_{\max } 2$ weeks post treatment.

Two other studies evaluated early PET-CT 3 months after SBRT $(13,24)$. In the largest series of 132 patients, residual uptake of more than 5 at 12 weeks after treatment signified increased risk of local failure (13). Median pre-SBRT $\mathrm{SUV}_{\max }$ of 7.65 (range=1.9-58.4) was similar to that for our population. Three patients in our study had an early $\mathrm{SUV}_{\text {max }}$ of more than 5 and did not experience any local recurrence; of these three patients, two had more than 2-fold reduction of their $\mathrm{SUV}_{\max }$, mentioned as being significant in another study of 82 patients with early-stage NSCLC treated with SBRT (24).

New approaches such as qualitative imagery are under investigation $(29,30)$ and new tracers such as fluoro-Lthymidine are being developed for detecting tumor proliferation with less sensitivity to inflammation.

\section{Conclusion}

According to these results, the metabolic response after SBRT is likely to be fast. Early PET-CT response, defined at a drop/stabilization in the $\mathrm{SUV}_{\max }$ by 2 to 3 months, appears to correlate with local control. The predictive nature of this response on the local cancer control needs to be confirmed in larger studies and with longer follow-up.

\section{References}

1 Chi A, Liao Z, Nguyen NP, Xu J, Stea B and Komaki R: Systemic review of the patterns of failure following stereotactic body radiation therapy in early-stage non-smallcell lung cancer: clinical implications. Radiother Oncol 94(1): 1-11, 2010.

2 Timmerman R, Paulus R, Galvin J, Michalski J, Straube W, Bradley J, Straube W, Bradley J, Fakiris A, Bezjak A, Videtic G, Johnstone D, Fowler J, Gore E and Choy H: Stereotactic body radiation therapy for inoperable early stage lung cancer. JAMA 303(11): 1070-1076, 2010.

3 Vansteenkiste J, Crinò L, Dooms C, Douillard JY, Faivre-Finn C, Lim E, Rocco G, Senan S, Van Schil P, Veronesi G, Stahel R, Peters S, Felip E and Panel Members: 2nd ESMO Consensus Conference on Lung Cancer: early-stage non-small-cell lung cancer consensus on diagnosis, treatment and follow-up. Ann Oncol 25(8): 1462-1474, 2014. 
4 Eisenhauer EA, Therasse P, Bogaerts J, Schwartz LH, Sargent D, Ford R, Dancey J, Arbuck S, Gwyther S, Mooney M, Rubinstein L, Shankar L, Dodd L, Kaplan R, Lacombe D and Verweij J: New response evaluation criteria in solid tumours: revised RECIST guideline (version 1.1). Eur J Cancer 45(2): 228-247, 2009.

5 Matsuo Y, Nagata Y, Mizowaki T, Takayama K, Sakamoto T, Sakamoto M, Norihisa Y and Hiraoka M: Evaluation of masslike consolidation after stereotactic body radiation therapy for lung tumors. Int J Clin Oncol 12(5): 356-362, 2007.

6 Takeda A, Kunieda E, Takeda T, Tanaka M, Sanuki N, Fujii H, Shigematsu $\mathrm{N}$ and Kubo A: Possible misinterpretation of demarcated solid patterns of radiation fibrosis on CT scans as tumor recurrence in patients receiving hypofractionated stereotactic radiotherapy for lung cancer. Int J Radiat Oncol Biol Phys 70(4): 1057-1065, 2008.

7 Dahele M, Palma D, Lagerwaard F, Slotman B and Senan S: Radiological changes after stereotactic radiotherapy for stage I lung cancer. J Thorac Oncol 6(7): 1221-1228, 2011.

8 Dunlap NE, Yang W, McIntosh A, Sheng K, Benedict SH, Read PW and Larner JM: Computed tomography-based anatomic assessment overestimates local tumor recurrence in patients with mass-like consolidation after stereotactic body radiotherapy for early-stage non-small cell lung cancer. Int J Radiat Oncol Biol Phys 84(5): 1071-1077, 2012.

9 Ursino S, Fiorica F, Colosimo C, Micucci M, Stefanelli A, Berretta M, Panareo S, De Biasi V, Feggi LM, Zini G and Cartei F: Metabolic responses in non-small cell lung cancer after hypofractionated stereotactic radiotherapy PET and hypofractionated radiotherapy. Eur Rev Med Pharmacol Sci 16(6): 755-762, 2012.

10 Takeda A, Kunieda E, Fujii H, Yokosuka N, Aoki Y, Oooka Y, Oku Y, Ohashi T, Sanuki N, Mizuno T and Ozawa Y: Evaluation for local failure by ${ }^{18} \mathrm{~F}$-FDG PET/CT in comparison with $\mathrm{CT}$ findings after stereotactic body radiotherapy (SBRT) for localized non-small-cell lung cancer. Lung Cancer 79(3): 248253,2013

11 Henderson MA, Hoopes DJ, Fletcher JW, Lin P-F, Tann M, Yiannoutsos CT, Williams MD, Fakiris AJ, McGarry RC and Timmerman RD: A pilot trial of serial ${ }^{18} \mathrm{~F}$-fluorodeoxyglucose positron emission tomography in patients with medically inoperable stage I non-small-cell lung cancer treated with hypofractionated stereotactic body radiotherapy. Int J Radiat Oncol Biol Phys 76(3): 789-795, 2010.

12 Essler M, Wantke J, Mayer B, Scheidhauer K, Bundschuh RA, Haller B, Astner ST, Molls M and Andratschke N: Positronemission tomography $\mathrm{CT}$ to identify local recurrence in stage I lung cancer patients 1 year after stereotactic body radiation therapy. Strahlenther Onkol 189(6): 495-501, 2013.

13 Bollineni VR, Widder J, Pruim J, Langendijk JA and Wiegman EM: Residual ${ }^{18}$ F-FDG-PET uptake 12 weeks after stereotactic ablative radiotherapy for stage I non-small-cell lung cancer predicts local control. Int J Radiat Oncol Biol Phys 83(4): e551555,2012

14 Huang K, Dahele M, Senan S, Guckenberger M, Rodrigues GB, Ward A, Boldt RG and Palma DA: Radiographic changes after lung stereotactic ablative radiotherapy (SABR) - can we distinguish recurrence from fibrosis? A systematic review of the literature. Radiother Oncol 102(3): 335-342, 2012.
15 Hoopes DJ, Tann M, Fletcher JW, Forquer JA, Lin P-F, Lo SS, Timmerman RD and McGarry RC: FDG-PET and stereotactic body radiotherapy (SBRT) for stage I non-small-cell lung cancer. Lung Cancer 56(2): 229-234, 2007.

16 Vahdat S, Oermann EK, Collins SP, Yu X, Abedalthagafi M, Debrito P, Suy S, Yousefi S, Gutierrez CJ, Chang T, Banovac F, Anderson ED, Esposito $G$ and Collins BT: CyberKnife radiosurgery for inoperable stage IA non-small cell lung cancer: ${ }^{18} \mathrm{~F}$-fluorodeoxyglucose positron emission tomography/ computed tomography serial tumor response assessment. J Hematol Oncol 3: 6-11, 2010.

17 Senthi S, Dahele M, van de Ven PM, Slotman BJ and Senan S: Late radiologic changes after stereotactic ablative radiotherapy for early stage lung cancer: a comparison of fixed-beam versus arc delivery techniques. Radiother Oncol 109(1): 77-81, 2013.

18 Palma DA, van Sörnsen de Koste J, Verbakel WFAR, Vincent A and Senan S: Lung density changes after stereotactic radiotherapy: a quantitative analysis in 50 patients. Int J Radiat Oncol Biol Phys 81(4): 974-978, 2011.

19 Minn H, Zasadny KR, Quint LE and Wahl RL: Lung cancer: reproducibility of quantitative measurements for evaluating 2[F-18]-fluoro-2-deoxy-D-glucose uptake at PET. Radiology 196(1): 167-173, 1995.

20 Boellaard R: Need for standardization of 18 F-FDG PET/CT for treatment response assessments. J Nucl Med 52(Suppl 2): 93S100S, 2011.

21 Nakajima N, Sugawara Y, Kataoka M, Hamamoto Y, Ochi T, Sakai S, Takahashi T, Kajihara M, Teramoto N, Yamashita M and Mochizuki T: Differentiation of tumor recurrence from radiation-induced pulmonary fibrosis after stereotactic ablative radiotherapy for lung cancer: characterization of ${ }^{18} \mathrm{~F}-\mathrm{FDG}$ PET/CT findings. Ann Nucl Med 27(3): 261-270, 2013.

22 Thie JA: Understanding the standardized uptake value, its methods, and implications for usage. J Nucl Med 45(9): 14311434, 2004

23 Schillaci O: Use of dual-point fluorodeoxyglucose imaging to enhance sensitivity and specificity. Semin Nucl Med 42(4): 267280, 2012.

24 Clarke K, Taremi M, Dahele M, Freeman M, Fung S, Franks K, Bezjak A, Brade A, Cho J, Hope A and Sun A: Stereotactic body radiotherapy (SBRT) for non-small cell lung cancer (NSCLC): Is FDG-PET a predictor of outcome? Radiother Oncol 104(1): 62-66, 2012.

25 Mattonen SA, Huang K, Ward AD, Senan S and Palma DA: New techniques for assessing response after hypofractionated radiotherapy for lung cancer. J Thorac Dis 6(4): 375-386, 2014.

26 Lovinfosse P, Janvary ZL, Coucke P, Jodogne S, Bernard C, Hatt M, Visvikis D, Jansen N, Duysinx B and Hustinx R: FDG $\mathrm{PET} / \mathrm{CT}$ texture analysis for predicting the outcome of lung cancer treated by stereotactic body radiation therapy. Eur J Nucl Med Mol Imaging 43(8): 1453-1460, 2016. 